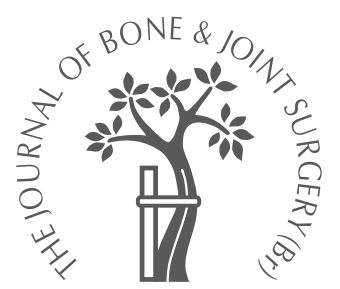

I. Tsionos, C. Leclercq, J-M. Rochet

From the Institut de la Main, Paris, France

I. Tsionos, MD, Fellow

C. Leclercq, MD,

Consultant

Institut de la Main, 6 Square

Jouvenet, 75016 Paris,

France.

J-M. Rochet, MD, Consultant

Centre de Rééducation Neurologique et de Réadaptation Fonctionnelle, Route de Liverdy 77170

Coubert, France.

Correspondence should be sent to $\mathrm{Dr}$ C. Leclercq.

(C)2004 British Editorial Society of Bone and Joint Surgery doi:10.1302/0301-620X.86B3. $14480 \$ 2.00$

$J$ Bone Joint Surg [Br] 2004;86-B:396-403. Received 22 April 2003; Accepted after revision 12 August 2003

\title{
Heterotopic ossification of the elbow in patients with burns
}

\author{
RESULTS AFTER EARLY EXCISION
}

Heterotopic ossification which may develop around the elbow in patients with burns may lead to severe functional impairment. We describe the outcome of early excision of such heterotopic ossification in 28 patients (35 elbows), undertaken as soon as the patient's general and local condition allowed. The mean age at operation was 42 years. The mean area of burnt body surface was $49 \%$. The mean pre-operative range of movement was $22^{\circ}$ in flexion/extension and $94^{\circ}$ in pronation/supination. The mean time between the burn and operation was 12 months with the median being 9.5. The mean follow-up period was for 21 months.

At the last review, the mean range of movement was $123^{\circ}$ in flexion/extension and $160^{\circ}$ in pronation/supination. Clinical evidence of recurrence was seen in four patients, occurring within the first two months after operation. Nevertheless, three of these elbows gained $60^{\circ}$ or more in flexion/extension and in pronation/supination. Based on this experience, we recommend early surgical treatment of heterotopic ossification of the elbow in patients with severe burns.

Heterotopic ossification (HO) is the formation of new bone in tissues which do not normally ossify. ${ }^{1}$ When it occurs around a joint it is usually referred to as 'periarticular ossification'.

$\mathrm{HO}$ is a rare but well-known complication of burns, occurring in $1 \%$ to $3 \%$ of such patients. ${ }^{2-6}$ In those who have sustained a thermal burn, the elbow appears to be the most commonly involved joint ${ }^{7,8}$ resulting in marked limitation of movement which is often associated with compression of the ulnar nerve. This may have secondary effects on the independence of the patient. Spontaneous resolution is unusual in adults. ${ }^{7}$

In view of the high incidence of recurrence after excision of HO from other joints, a delay in operative treatment is usually advised until the bony mass reaches radiological maturation and biological silence. ${ }^{9-13}$ This means a delay of 18 to 24 months $^{8,13}$ or more, although this period seems to be arbitrary. Such a delay deprives the patient of essential functional capabilities for a long time. It may also increase soft-tissue contractures, decrease muscle function and yield less satisfactory restoration of mobility of the joint once the mass of HO has been excised.

We describe the results of the early excision of $\mathrm{HO}$ around the elbow in 28 patients $(35$ elbows) with severe burns.

\section{Patients and Methods}

Between 1992 and 2001, a consecutive series of 28 patients with burns was treated surgically for $\mathrm{HO}$ involving 35 elbows. All were operated on by the same surgeon (CL), and had the same rehabilitation. The medical records were reviewed retrospectively. There were 19 men and nine women with a mean age of 42 years (17 to 59). The right elbow was affected in 11 patients, the left in ten and both elbows in seven. The mean amount of body surface which was burnt was $49 \%$ (12 to 83 ). In all patients except one, the area of the elbow had been affected by the burn.

The mean delay between the burn and surgery was 12 months (4 to 43.5) (Fig. 1). The median delay was 9.5 months and 20 elbows were operated on earlier than 9.6 months after the burn. Nevertheless, excision was considerably delayed in some patients because concomitant medical conditions, such as respiratory failure and neurological lesions, lead to confinement in bed. An elevated level of serum alkaline phosphatase or a positive three-phase bone scan was not considered to be a contraindication to early excision of the HO. Care was taken to wait until all the burnt skin had healed around the elbow, but not necessarily on other parts of the body. 


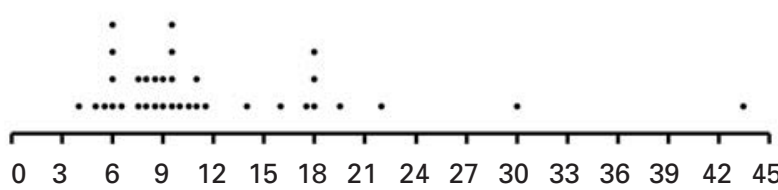

Fig. 1

Distribution of operated elbows in relation to delay (in months) between the burn and surgery.

Of the 28 patients, 26 had been intubated for a period of time which varied from two to 14 weeks before admission to the Rehabilitation Centre, either for respiratory failure or for relief from pain and nursing care.

Pre-operative evaluation. The active and passive range of movement of the elbow was measured with a goniometer before and after operation.

Pre-operative assessment included standard anteroposterior (AP) and lateral radiographs. CT of the affected elbow with three-dimensional (3-D) reconstruction was routinely performed after 1995 in order to assess the site and extent of the HO. The patients were divided into three groups according to the site: group A (28 elbows) with involvement only of the humeroulnar joint (HUJ) (Fig. 2); group B (one elbow) with involvement only of the proximal radio- ulnar joint (PRUJ); and group C (six elbows) with involvement of both joints (Fig. 3). All HUJ ossifications involved the medial aspect of the joint and in two cases extended laterally to the olecranon fossa and the lateral epicondyle of the humerus. HO of the PRUJ developed between the bicipital tuberosity and the proximal ulna.

In 11 elbows $(31 \%)$ there were associated symptoms and/or signs of compression of the ulnar nerve. The deficit was sensory only in six and mixed in five, with two complete and three partial lesions.

Ten patients (14 elbows) had a more generalised dysfunction of peripheral nerves affecting the upper limb.

Operative technique. We undertook surgery early as soon as the patient's general health allowed and the skin around the elbow had healed.

All patients were operated on under axillary block, unless the patient's health or expected intolerance to peroperative positioning of the upper limb made general anaesthesia more suitable. A tourniquet was used routinely.

In group A a medial longitudinal incision was used with elevation and protection of the ulnar nerve. When the nerve was found to be encased in $\mathrm{HO}$ it was identified proximally and distally to the bony mass. Using osteotomes, two parallel grooves were prepared, along its presumed course, and the tunnel was deroofed from proximal to distal. In group $\mathrm{B}$ an anterior approach was used. In group $\mathrm{C}$, a combination of a medial with either an anterior or a posterolateral approach was used.

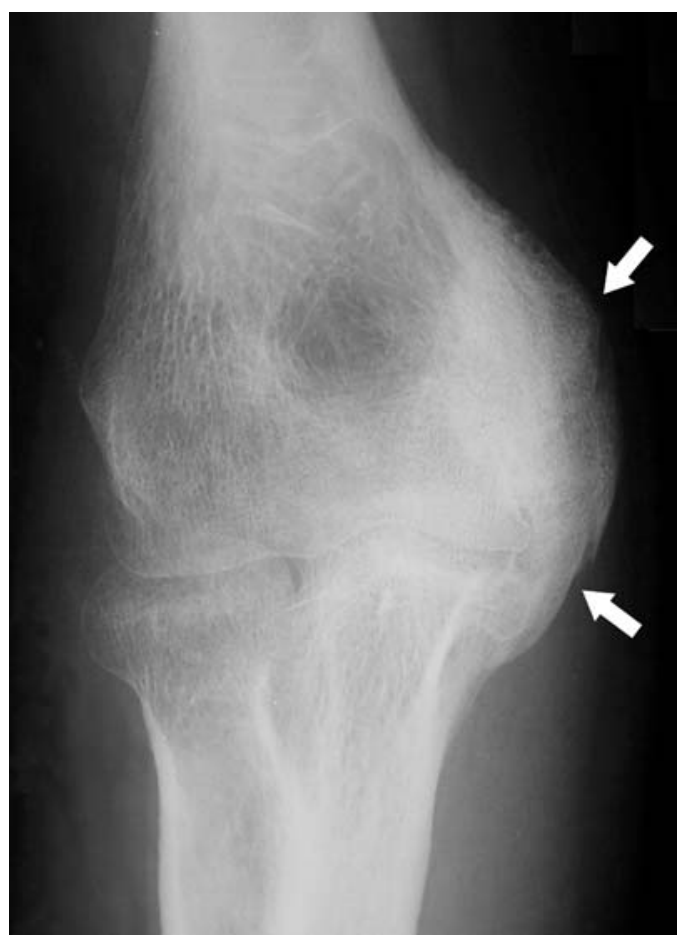

Fig. 2a

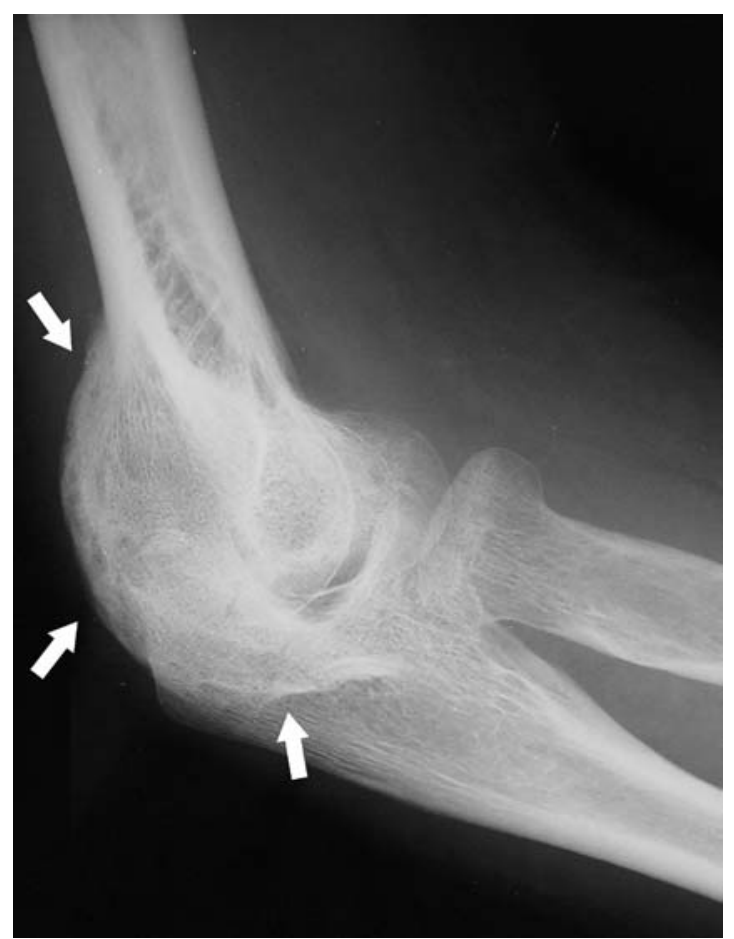

Fig. $2 b$

Pre-operative a) AP and b) lateral radiographs showing $\mathrm{HO}$ bridging the humeroulnar joint posteromedially (arrows). 


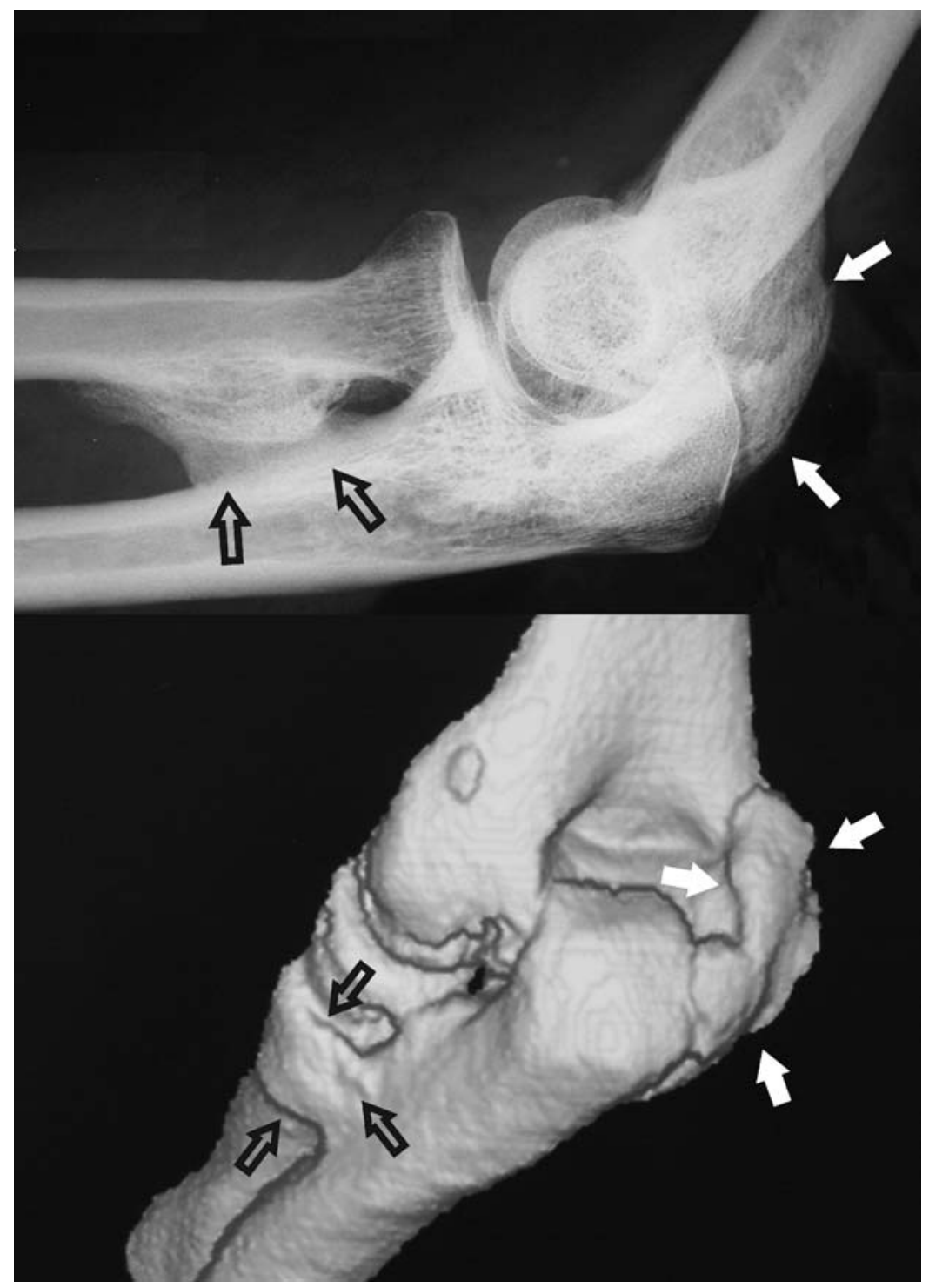

Fig. 3a

Pre-operative a) lateral radiograph and b) 3-D CT reconstruction showing $\mathrm{HO}$ affecting the humeroulnar (white arrows) and proximal radioulnar (black arrows) joints.

Fig. $3 b$

In all cases excision of the heterotopic bone was as complete as possible and not merely restricted to that part which prevented movement of the elbow. An effort was made to restore the normal contour of the bone especially at the medial epicondyle.

Difficulty was often met in determining the margins of the ossification. In HUJ ossification, the limits between heterotopic and normal bone were best seen just distal to the medial epicondyle. At this level, the insertion of the flexor-pronator mass usually separated normal bone from the more superficial heterotopic bone. However, at the level of the distal humeral metaphysis, no such limit could be clearly established. Distal to the medial epicondyle, the heterotopic mass involved the medial collateral ligament, which was usually unidentifiable. Nevertheless, no patient had instability of the elbow after operation.

After excision of HUJ ossification, the ulnar nerve was transposed anteriorly in a subcutaneous position in 30

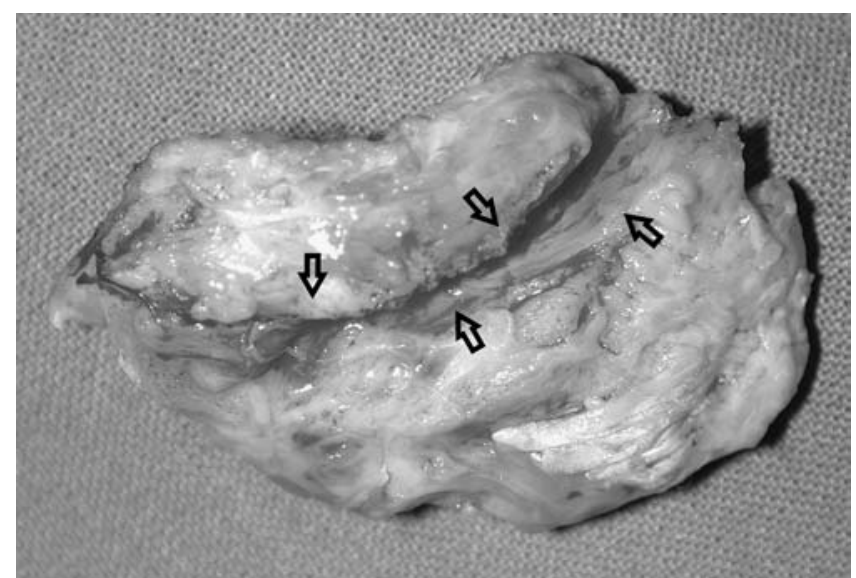

Fig. 4

Photograph showing incomplete osseous tunnel (arrows) partially encasing the ulnar nerve, in an excised mass of $\mathrm{HO}$. 


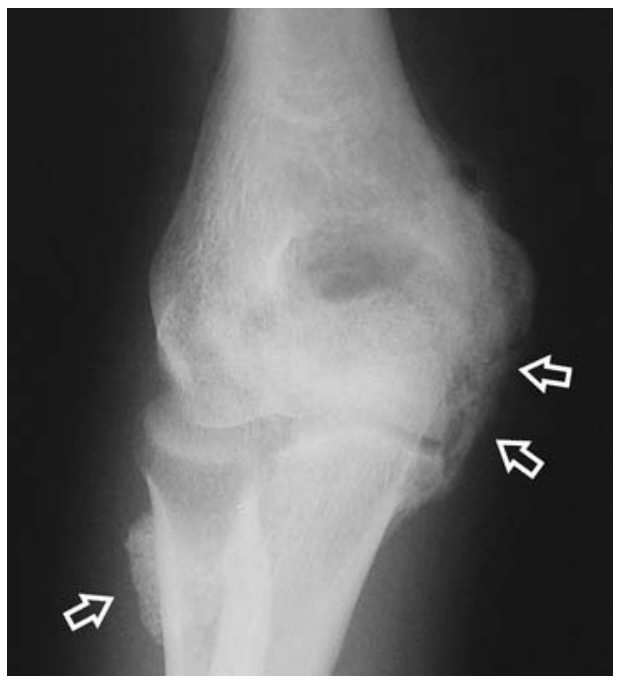

Fig. $5 a$

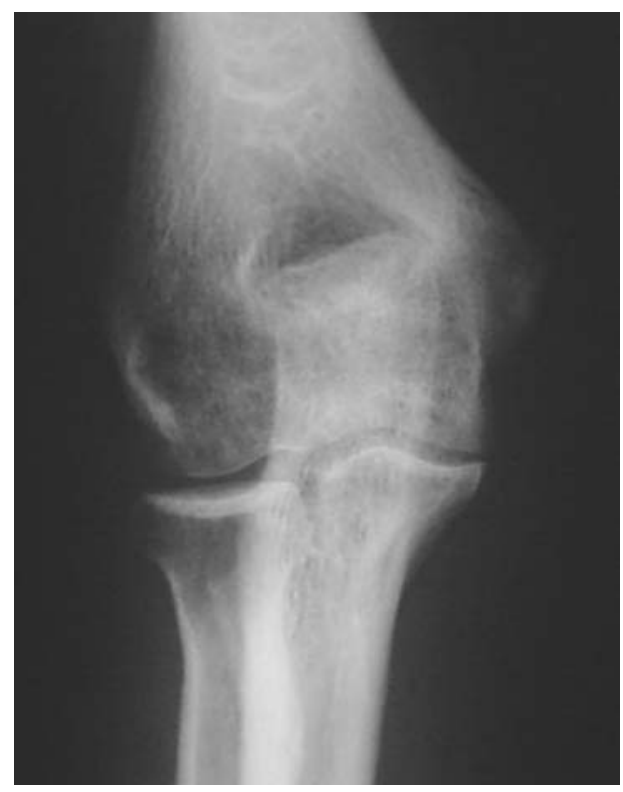

Fig. 5c

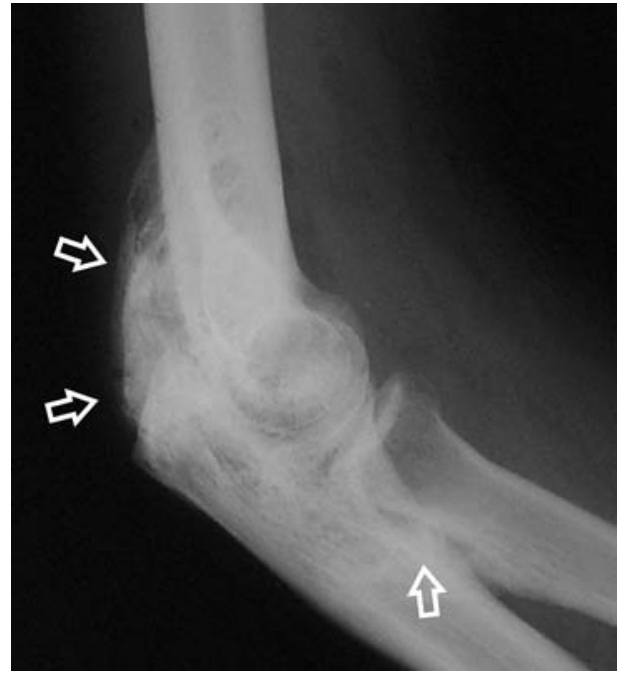

Fig. $5 b$

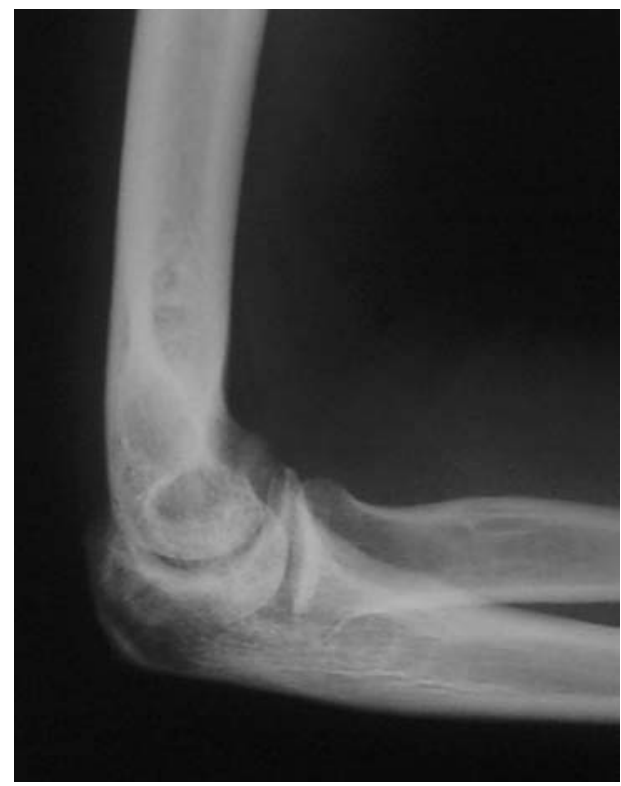

Fig. 5d

Pre-operative a) AP and b) lateral radiographs showing $\mathrm{HO}$ of the humeroulnar and proximal radio-ulnar joints (arrows). Figures $5 \mathrm{c}$ and $5 \mathrm{~d}$ - post-operative c) AP and d) lateral radiographs of the same patient at four months showing absence of periarticular ossification.

elbows. In five, vascularised soft tissues could be interposed between the exposed bone and the nerve.

In the immediate post-operative period the arm was positioned in plaster splints, in maximum flexion or extension, alternating every four hours. Continuous passive motion in flexion/extension and pronation/supination was started on the second day for eight hours a day and continued for three to four weeks, thereafter diminishing for a further two to four weeks. For those patients with persistent post-operative limitation of pronation and supination, this was supplemented by the use of static splinting alternating in pronation and supination. Active physiotherapy started one week after operation. Indomethacin (75 mg/day) in combination with $\mathrm{H}_{2}$-antagonists was given for three weeks after operation. Clinical and radiological assessment was undertaken monthly during the stay in hospital, then at intervals of approximately six months.

Statistical analysis. This was performed using a single or paired $t$-test according to the groups compared. Non-quantitative data were compared using the chi-squared test. The level of statistical significance was set at 0.05 . 


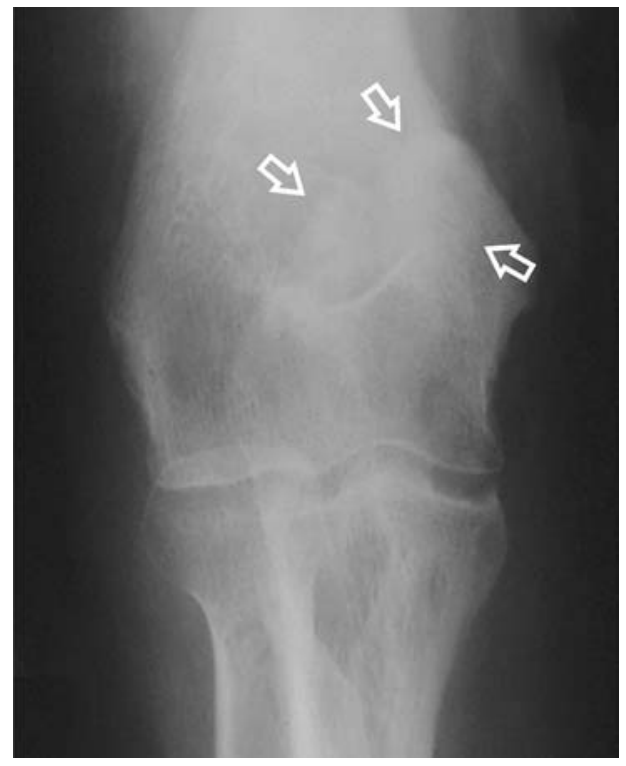

Fig. 6a

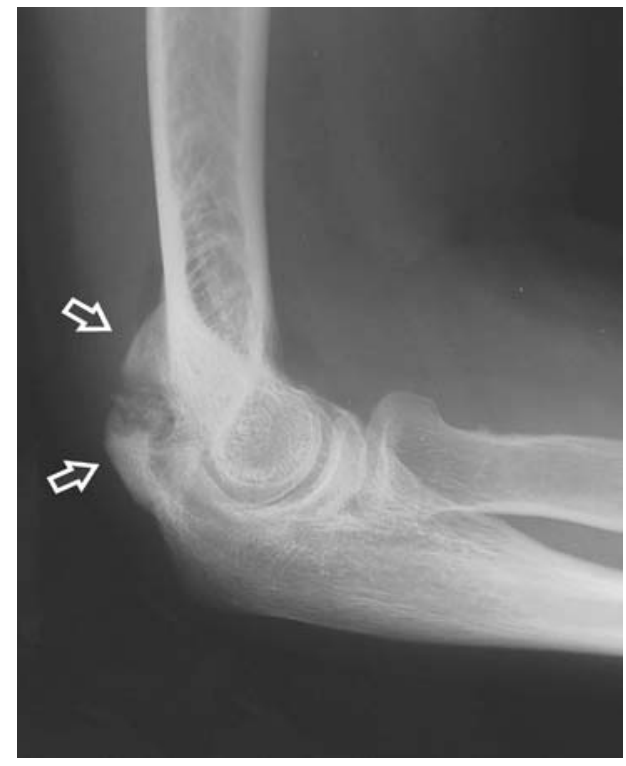

Fig. 6b

AP a) and lateral b) radiographs at eight months after operation of the case presented in Figure 2 (case 1, Table III), showing a recurrence limited to the posterior part of the HUJ (arrows).

Table I. Mean (SEM; degrees) range of pronation and supination. Statistical significance refers to differences between pre-operative and latest follow-up values (paired $t$-test). For definition of groups $A, B$ and $C$ see text

\begin{tabular}{|c|c|c|c|c|c|c|c|}
\hline Groups & $\begin{array}{l}\text { Number of } \\
\text { elbows }\end{array}$ & Pre-op & $\begin{array}{l}\text { Immediately } \\
\text { post-op }\end{array}$ & $\begin{array}{l}\text { Latest } \\
\text { follow-up }\end{array}$ & Mean gain & $\begin{array}{l}\text { Statistic } \\
\text { significa }\end{array}$ & $\begin{array}{l}\text { cal } \\
\text { ance }\end{array}$ \\
\hline$A+B+C$ & 35 & $94 \quad(10)$ & 160 & 160 & $66 \quad(10)$ & 1.680 & $10^{-8}$ \\
\hline$B+C$ & 7 & $19 \quad(9)$ & 159 & 144 (17) & $125 \quad(26)$ & 0.00281 & \\
\hline A & 28 & 113 & 161 & 164 & (8) & 1.750 & $10^{-6}$ \\
\hline
\end{tabular}

Table II. Mean (SEM; degrees) range of flexion and extension. Statistical significance refers to differences between pre-operative and latest follow-up values (paired $t$-test). For definitions of groups $A, B$ and $C$ see text

\begin{tabular}{|c|c|c|c|c|c|c|c|c|c|c|}
\hline \multirow{2}{*}{$\frac{\text { Group }}{A+B+C}$} & \multirow{2}{*}{$\begin{array}{l}\begin{array}{l}\text { Number } \\
\text { of elbows }\end{array} \\
35\end{array}$} & \multirow{2}{*}{$\begin{array}{r}\text { Pre-op } \\
22(5)\end{array}$} & \multicolumn{2}{|c|}{$\begin{array}{l}\text { Immediately } \\
\text { post-op }\end{array}$} & \multicolumn{2}{|c|}{$\begin{array}{l}\text { Latest } \\
\text { follow-up }\end{array}$} & \multicolumn{2}{|c|}{$\begin{array}{l}\text { Mean } \\
\text { gain }\end{array}$} & \multicolumn{2}{|c|}{$\begin{array}{l}\text { Statistical } \\
\text { significance }\end{array}$} \\
\hline & & & 113 & (4) & 123 & (5) & 101 & (6) & 1.095 & $10^{-17}$ \\
\hline$A+C$ & 34 & $18(4)$ & 112 & (4) & 123 & (5) & 105 & (6) & 2.537 & $10^{-19}$ \\
\hline B & 1 & 145 & 145 & & 140 & & -5 & & & - \\
\hline
\end{tabular}

\section{Results}

Operative findings. In 22 elbows the nerve was partially or totally encased in an osseous or fibro-osseous tunnel (Fig. 4). This group included ten of the 11 patients with pre-operative signs of entrapment of the ulnar nerve. In the 11th patient, the nerve was compressed by the bony mass. There was an 'hour-glass' deformity of the nerve in the five patients with a mixed deficit.

Function of the joint. The mean follow-up was for 21 months (2 to 93). Table I summarises the mean range of flexion and extension before and immediately after operation and at the latest follow-up. Group $\mathrm{A}+\mathrm{C}$ represents patients with pre-operative involvement of the HUJ, for which a mean gain of $105^{\circ}$ was obtained.
Table II summarises the mean range of pronation and supination. In cases in which the PRUJ was involved (groups $\mathrm{B}+\mathrm{C}$ ), there was a mean gain of $125^{\circ}$. In patients without involvement of the PRUJ (group A), a mean gain of $51^{\circ}$ was nevertheless achieved.

Function of the ulnar nerve. All 11 patients with pre-operative compression of the ulnar nerve had partial or complete restoration of nerve function, as demonstrated by clinical and/or electrophysiological testing, including two who had recurrent HO. All sensory deficits had resolved at the final review. Partial motor deficits had been restored and the two complete motor paralyses had substantially improved.

Recurrences. The presence of ossified periarticular tissue on post-operative radiographs was a common finding, being 


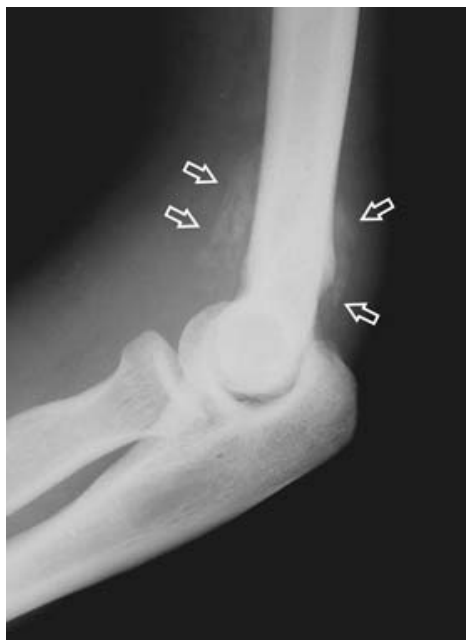

Fig. $7 a$

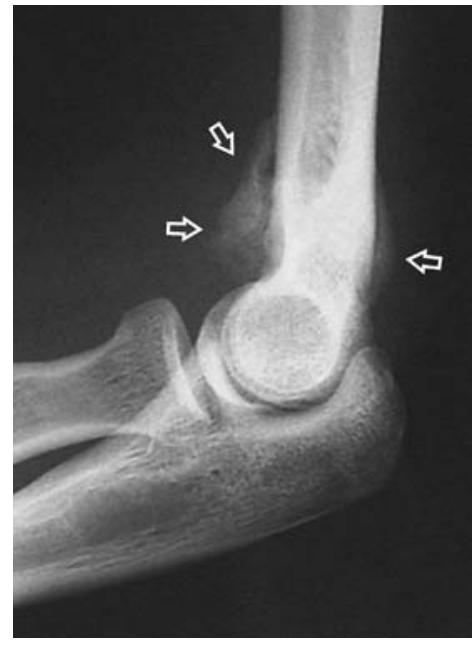

Fig. $7 b$

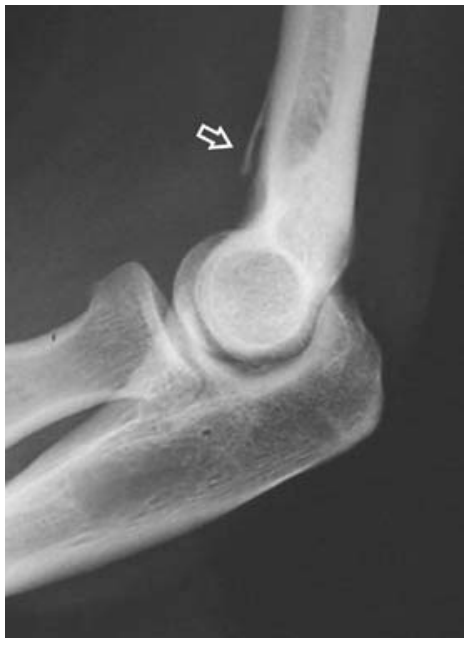

Fig. 7c

Lateral radiographs at a) seven weeks, b) three months and c) 20 months after excision of a humeroulnar ossification, showing the early appearance and reduction in size of further ossification.

Table III. Range of movement (degrees) of the elbow in the four patients with true recurrence

\begin{tabular}{|c|c|c|c|c|c|c|c|c|c|}
\hline \multirow[b]{2}{*}{ Cases } & \multirow[b]{2}{*}{ Joint involved* } & \multicolumn{2}{|c|}{ Pre-opt } & \multicolumn{2}{|c|}{$\begin{array}{l}\text { Immediately } \\
\text { post-op }\end{array}$} & \multicolumn{2}{|c|}{ Latest follow-up } & \multicolumn{2}{|c|}{$\begin{array}{l}\text { Gain in range } \\
\text { of movement }\end{array}$} \\
\hline & & FI/ext & Pr/sup & Fl/ext & $\operatorname{Pr} /$ sup & FI/ext & $\operatorname{Pr} /$ sup & $\mathrm{FI} / \mathrm{ext}$ & $\mathrm{Pr} /$ sup \\
\hline 1 & HUJ & 0 & 100 & 115 & 170 & 80 & 165 & 80 & 65 \\
\hline 2 & HUJ & 0 & 100 & 120 & 170 & 60 & 160 & 60 & 60 \\
\hline 3 & HUJ & 0 & 115 & 90 & 170 & 95 & 180 & 95 & 65 \\
\hline 4 & HUJ/PRUJ & 0 & 0 & 135 & 170 & 0 & 180 & 0 & 180 \\
\hline
\end{tabular}

* HUJ, humeroulnar joint; PRUJ, proximal radio-ulnar joint

$\dagger \mathrm{fl} / \mathrm{ext}$, range of movement in flexion/extension; pr/sup, range of movement in pronation/supination

Table IV. Comparison of variables between recurrent and non-recurrent cases. $P$ values are calculated for true recurrences (four cases) versus all other elbows

\begin{tabular}{ll}
\hline Variable & p value \\
\hline Gender & 0.769 \\
Age & 0.990 \\
Body surface area burnt & 0.358 \\
Delay (burn to operation) & 0.732 \\
'Complete joint blockage' & 0.039 \\
Neurological impairment affecting the & 0.759 \\
mobility of the upper limb & \\
HO elsewhere in the body & 0.212 \\
Incompliance to post-op physiotherapy & 0.0008 \\
\hline
\end{tabular}

detected in 25 elbows $(71 \%)$. In ten elbows it was absent (Fig. 5). In four elbows, this ossification represented some of the initial $\mathrm{HO}$ which had not been excised. In eight elbows, it resembled newly formed osseous tissue in continuity with normal bone. In four of these, it grew during the follow-up period and clinically represented recurrence of the $\mathrm{HO}$ with further restriction of movement. These cases were considered to be 'true recurrences' (Fig. 6). In two other elbows, this growth, although present on radiographs did not limit the function of the elbow and the range of movement remained as before operation. Finally, ossification was seen on early post-operative radiographs of two elbows and appeared to reduce in size with the passage of time (Fig. 7) but were clinically silent.

In 13 elbows, ossified tissue was visible on post-operative radiographs as small areas of calcification in soft tissue, away from normal bone cortex. In none did it affect the function of the elbow. We were not able to determine whether this represented ossification which had not been removed at operation or recurrent formation. However, its location away from the normal bone cortex suggested the former.

Data concerning the pre- and post-operative range of movement of the elbow in the four patients with a true recurrence are shown in Table III. All recurrences appeared within two months of surgery. Despite the recurrence, in three patients (cases 1 to 3 ) the final range of movement was considerably improved. In the fourth (case 4) the recurrence blocked the HUJ completely but spared the PRUJ.

An attempt was made to identify factors related to recurrence (Table IV). No significant difference was found regarding gender, age, the area of the body surface burnt, delay to operation, other neurological impairment and the 
presence of $\mathrm{HO}$ elsewhere. Considering the delay between the burn and operation, the mean values for recurrent and non-recurrent cases were 11 and 12 months, respectively, which was not statistically significant.

As regards pre-operative limitation of movement of the elbow, those joints with a true recurrence were blocked before operation with $<10^{\circ}$ of movement, as were 14 of the 31 without a true recurrence. The difference was statistically significant.

Finally, in all four elbows with a true recurrence there was marked post-operative pain and/or reluctance of the patient to follow the rigorous physiotherapy programme whereas, this occurred in only six of the 31 elbows without a true recurrence. This difference was statistically significant.

Re-operations. We performed two further operations in this series, both for $\mathrm{HO}$ of the PRUJ. In one with combined HUJ and PRUJ ossifications (group C), the latter was poorly visible before operation and was overlooked. Excision of the HUJ ossification proved to be useful in restoring flexion and extension of the elbow but there remained severe limitation of supination. The PRUJ ossification was subsequently excised through a posterolateral approach, with a gain of $20^{\circ}$ in supination.

In the second patient, which was the only one in group B, with $\mathrm{HO}$ localised to the PRUJ, excision was undertaken six months after the burn through an anterior approach. This proved to be incomplete, leaving a substantial amount of posterior ossification which was removed through a posterolateral approach, restoring normal movement.

Neither of these patients had had a 3-D CT reconstruction before operation.

The patient with complete recurrence of bridging of the HUJ (case 4, Table III) had further surgery elsewhere with restoration of $90^{\circ}$ of flexion/extension.

\section{Discussion}

The function of the upper limb depends on movement of the elbow. Morrey, Askew and Chao ${ }^{14}$ showed that $100^{\circ}$ of flexion/extension (30 to 130 ) and $100^{\circ}$ of pronation/supination with $50^{\circ}$ supination and $50^{\circ}$ pronation are essential for the elbow to perform most daily activities. Vasen et a $1^{15}$ considered the functional range of flexion/extension to be $75^{\circ}$ to $120^{\circ}$. Thus, all our patients were functionally handicapped before operation.

Our findings confirm those of Evans ${ }^{7}$ that $\mathrm{HO}$ of the elbow typically occurs between the medial epicondylar ridge of the humerus and the olecranon.

In patients without involvement of the PRUJ (group A), a statistically significant gain in pronation and supination was nevertheless achieved. We believe that freeing the HUJ in these patients gave a mechanical advantage to the muscles participating in rotation of the forearm and rendered physiotherapy more efficient.

Concerning impairment of the ulnar nerve, a return of function can be expected, even in cases of a mixed deficit.
Although the persistence or reappearance of periarticular ossification was common after operation, this was associated with a clinical recurrence in only four elbows. Thus the term true recurrence should be reserved for those cases in which recurrent radiological evidence of ossification is combined with a secondary loss of the gained range of movement. In one patient true recurrence led to a complete block of flexion and extension of the elbow whereas in the other three the loss was only partial, and the movement which had been gained represented a considerable functional improvement. In these four cases, the post-operative radiological appearance was that of ossification growing in continuity with normal bone cortex. This appearance should alert the surgeon to a possible recurrence, whereas, none of those cases with calcification in soft tissue led to a true recurrence.

Among pre-operative factors, a complete block of flexion and extension was significantly related to a true recurrence. All true recurrences occurred in elbows with a continuous osseous bridge between the humerus and ulna (Fig. 1). The amount of ossified tissue and the presence of joint ankylosis have been previously proposed as factors predicting recurrence in patients suffering from injuries of the spinal cord. ${ }^{13}$ It may be that marked post-operative pain is associated with true recurrence.

We found pre-operative 3-D CT reconstruction to be helpful in analysing the extent of the $\mathrm{HO}$ and deciding on the surgical approach, thus avoiding incomplete excision and further operations. It also demonstrated that, when the HO involved the PRUJ, it was always posteriorly, thus requiring a posterolateral approach.

Radiotherapy was not used for the prevention of recurrence but instead, indomethacin was given. Experience with the use of either in patient with burns is lacking. ${ }^{16-18}$

There are few reports on the surgical treatment of $\mathrm{HO}$ of the elbow in patients with burns, ${ }^{3,4,6,19-24}$ with some inconsistent results. ${ }^{3,20,22,24}$ To our knowledge this series is the largest published to date.

Concerning the timing of the intervention, the literature on $\mathrm{HO}$ in patients with injury to the spinal cord suggests that the level of serum alkaline phosphatase and bone scanning can be used as markers of the biological activity of HO, ${ }^{9-11}$ although it is recognised that it may take several years before they return to normal. A comparison of serial bone scans can be more indicative of the maturing of the HO than one single scan. ${ }^{8,11}$ The level of serum alkaline phosphatase has proved to be unreliably related to the presence of $\mathrm{HO}^{19}$ in the elbows of patients with burns. Garland et $\mathrm{al}^{25}$ stated that, in the elbow, HO usually did not represent enough bone tissue to elevate the level of serum alkaline phosphatase. As to the minimum delay of 12 to 18 months between the appearance of $\mathrm{HO}$ and surgery, which has been arbitrarily recommended by some, ${ }^{12,25,26}$ it appears to be more applicable to patients with head injuries in whom such a time interval allows optimal neurological recovery, which is essential for post-operative mobilisa- 
tion. ${ }^{8,13,25}$ Additionally, Garland and Orwin ${ }^{27}$ found that the maturity of $\mathrm{HO}$ in patients with injury to the spinal cord, assessed by routine radiographs and bone scanning, did not affect the incidence of recurrence. There have recently been some reports of patients with head injuries or local trauma who developed $\mathrm{HO}$ of the elbow and underwent early surgery with encouraging results. ${ }^{28-31}$

In our series of 28 patients with burns (35 elbows), we performed an excision of the $\mathrm{HO}$ with a mean delay of 12 months; in 20 cases the delay was $\leq 9.5$ months. All patients benefited from rigorous post-operative physiotherapy and satisfactory results were obtained with regard to the restoration of the function of the elbow and improvement in quality of life.

No benefits in any form have been received or will be received from a commercial party related directly or indirectly to the subject of this article.

\section{References}

1. Sawyer JR, Myers MA, Rosier RN, Puzas JE. Heterotopic ossification: clinical and cellular aspects. Calcif Tissue Int 1991;208-15.

2. Johnson JTH. Atypical myositis ossificans. J Bone Joint Surg [Am]1957;39-A:189-94.

3. Kolar J, Vrabec R. Periarticular soft-tissue changes as a late consequence of burns. J Bone Joint Surg [Am] 1959;41-A:103-11.

4. Evans EB, Smith JR. Bone and joint changes following burns: a roentgenographic study-preliminary report. J Bone Joint Surg [Am]1959;41-A:785-99.

5. Elledge ES, Smith AA, McManus WF, Pruitt BA. Heterotopic bone formation in burned patients. J Trauma 1988;28:684-7.

6. Peterson SL, Mani MM, Crawford CM, Neff JR, Hibert JM. Postburn heterotopic ossification: insights for management decision making. J Trauma 1989;29:365-9.

7. Evans EB. Heterotopic formation in thermal burns. Clin Orthop 1991;263:94-101.

8. Summerfield SL, DiGiovani C, Weiss AC. Heterotopic ossification of the elbow. J Shoulder Elbow Surg 1997;6:321-32.

9. Furman R, Nicholas JJ, Jivoff L. Elevation of the serum alkaline phosphatase coincident with ectopic-bone formation in paraplegic patients. J Bone Joint Surg [Am] 1970;52-A:1131-7.

10. Hsu JD, Sakimura I, Stauffer ES. Heterotopic ossification around the hip joint in spinal cord injured patients. Clin Orthop 1975;112:165-9.

11. Tibone J, Sakimura I, Nickel VL, Hsu JD. Heterotopic ossification around the hip in spinal cord-injured patients: a long-term follow-up study. J Bone Joint Surg [Am] 1978;60-A:769-75.
12. Roberts JB, Pankratz DG. The surgical treatment of heterotopic ossification at the elbow following long-term coma. J Bone Joint Surg [Am] 1979;61-A:760-3.

13. Garland DE. A clinical perspective on common forms of acquired heterotopic ossification. Clin Orthop 1991;263:13-29.

14. Morrey BF, Askew LJ, Chao EY. A biomechanical study of normal functional elbow motion. J Bone Joint Surg [Am] 1981;63-A:872-7.

15. Vasen AP, Lasey SH, Keith MW, Shaffer JW. Functional range of motion of the elbow. J Hand Surg [Am] 1995;20:288-92.

16. Kjaersgaard-Andersen $\mathbf{P}$, Schmidt SA. Total hip arthroplasty: the role of antiinflammatory medications in the prevention of heterotopic ossification. Clin Orthop 1991;263:78-86

17. Ayers DC, Pellegrini VD Jr, Evarts CM. Prevention of heterotopic ossification in high-risk patients by radiation therapy. Clin Orthop 1991;263:87-93.

18. McAuliffe JA, Wolfson AH. Early excision of hererotopic ossification about the elbow followed by radiation therapy. J Bone Joint Surg [Am] 1997;79-A:749-55.

19. Munster AM, Bruck HM, Johns LA, et al. Heterotopic calcification following burns: a prospective study. J Trauma 1972;12:1071-4.

20. Hoffer MM, Brody G, Ferlic F. Excision of heterotopic ossification about elbows in patients with thermal injury. J Trauma 1978;18:667-70.

21. Tepperman PS, Hilbert L, Peters WJ, Pritzker KPH. Heterotopic ossification in burns. J Burn Care Rehabil 1984;5:283-7.

22. Vorenkamp SE, Nelson TL. Ulnar nerve entrapment due to heterotopic bone formation after a severe burn. J Hand Surg [Am] 1987;12:378-80.

23. Peters WJ. Heterotopic ossification: can early surgery be performed, with a positive bone scan? J Burn Care Rehabil 1990;11:318-21.

24. Djurickovic S, Meek RN, Snelling CFT, et al. Range of motion and complications after postburn heterotopic bone excision about the elbow. J Trauma 1996;41:825-30.

25. Garland DE, Hanscom DA, Keenan M, Smith C, Moore T. Resection of heterotopic ossification in the adult with head trauma. J Bone Joint Surg [Am] 1985;67-A: $1261-9$

26. Hastings H 2nd, Graham TJ. The classification and treatment of heterotopic ossification about the elbow and forearm. Hand Clin 1994;10:417-37.

27. Garland DE, Orwin JF. Resection of heterotopic ossification in patients with spinal cord injuries. Clin Orthop 1989;242:169-76.

28. Berard E, Cypres A. Chirurgie fonctionelle précoce des para-ostéo-arthropathies neurogènes. In: Pélissier J, Minaire P, Chantraine A, eds. Les para-ostéo-arthropathies neurogènes: collection de pathologie locomotrice. Paris, Masson, 1995:161-6.

29. Fyon JP, Boucand MH, Lecuire F, et al. Le point sur la chirurgie fonctionelle précoce des POA. In: Pélissier J, Minaire P, Chantraine A, eds. Les para-ostéo-arthropathies neurogènes: collection de pathologie locomotrice. Paris, Masson, 1995:167-9.

30. Denormandie P, Viguie G, Denys P, Dizien 0, Carlier R. Results of excision of heterotopic new bone around the elbow in patients with head injuries: a series of 25 cases. Ann Chir Main 1999;18:99-107.

31. Moritomo H, Tada K, Yoshida T. Early, wide excision of heterotopic ossification in the medial elbow. J Shoulder Elbow Surg 2001;10:164-8. 